\title{
FIN DE PARTIDA DE SAMUEL BECKETT: LA SOBERANÍA DEL LENGUAJE Y EL JUEGO METATEATRAL
}

\author{
Carolina Brncic \\ Universidad de Chile \\ cbrncic@gmail.com
}

\section{RESUMEN / ABSTRACT}

El artículo analiza Fin de partida de Samuel Beckett como obra metateatral. Para abordar el problema del género se examinan cuatro enfoques críticos relevantes: la teoría de Martin Esslin sobre el Teatro del Absurdo, la interpretación de Theodor Adorno como drama de la descomposición, la lectura de Christoph Menke como una tragedia de la representación y la propuesta de Lionel Abel sobre el metateatro. A partir de la definición señalada por Abel, se analiza la obra atendiendo a dos dimensiones paradigmáticas: la noción de juego representacional como drama autorreflexivo y la soberanía del lenguaje como soporte dramático.

PALABRAS ClAVE: juego teatral, artificio, metateatro, autorreflexividad, diálogo.

The article studies Samuel Beckett's Endgame as a meta-theatrical play. To examine the problem of genre four critical approaches are focussed: Martin Esslin's theory about the Theatre of the Absurd, Theodor Adorno's interpretation as a drama of decomposition, Christoph Menke's reading as a tragedy of representation and Lionel Abel's metatheatre proposal. In relation to the definition provided by Abel, Beckett's play is analized in the light of two major dimensions: the notion of the representational play as a self-reflexive drama and the distinction of language as a dramatic support.

KEY WORDS: representational play, metatheatre, self-reflexive drama, dialogical speech. 
Desde que Martin Esslin en su ya afamada publicación de 1961, acuñara la expresión "Teatro del absurdo" para caracterizar las piezas dramáticas de Samuel Beckett, Eugène Ionesco, Arthur Adamov, Jean Genet, entre otros, las obras de Beckett han sido una y otra vez revisitadas para discutir la pertinencia de dicha denominación a la luz de los presupuestos establecidos por el crítico.

Según Esslin, las características que cohesionan esta actitud vital del teatro contemporáneo -y que, en ningún caso configura un movimiento o escuelaserían: la ruptura con la tradición decimonónica del drama europeo y la oposición a un teatro existencialista o de situaciones en el abandono de las convenciones dramáticas y el razonamiento lógico discursivo, para privilegiar un 'teatro' que explora las potencialidades escénicas y del lenguaje, traduciendo así la angustia metafísica y la irracionalidad de la condición humana en 'imágenes' (cfr. Esslin 14-17). La importancia que cobra la desintegración de la acción y del lenguaje a través del diálogo dramático, constituyen para Esslin los dos elementos nucleares que en su relación de 'contrapunto' hacen de Fin de partida una pieza del teatro del absurdo. Para nosotros, en concordancia con otros críticos, la relación entre lenguaje y acción atrae el problema del género de la obra que, en su autorreflexividad devuelve el predominio del texto al teatro, dotando a la palabra de una carga y sentido dramáticos.

La pieza se muestra como el juego rutinario entre dos personajes, el ciego y paralítico Hamm y su sirviente Clov al interior de un refugio, el home, que parece ser el último reducto de vida tras una aparente catástrofe que ha acabado con el ciclo natural: el sol, las mareas, la germinación. Recluidos en un espacio reducido y acompañados por los progenitores de Hamm, Nagg y Nell, ancianos mutilados de piernas confinados en dos tachos de basura, el acontecer se reduce a hacer pasar el tiempo hablando. La probable partida de Clov se convierte en el único "tema" que matiza un diálogo intrascendente e incesante. En la interrogación, réplica, negación e impugnación, el diálogo pierde su función comunicativa, y la cháchara vacía e inconducente se despoja de su condición de acción verbal, por cuanto la constante amenaza de abandono no se concreta. Así, cada día se presenta en el refugio como una 'sobrevida' frente al infierno exterior -el otro-, pero por sobre todo, frente a la tortura que significan unos para otros, determinados a permanecer juntos en este infierno de tres paredes ${ }^{1}$.

La denominación de 'tres paredes' remite a la noción dramática del 'teatro de la cuarta pared', propia del teatro clásico y decimonónico que se caracteriza por presentar la 
Para Esslin, Fin de partida, así como otras obras del teatro del absurdo, muestra la desintegración del lenguaje como vehículo significante y medio de comunicación que, en un juego incesante de repetición y vaciamiento, exhibe sus propias limitaciones e incapacidad para dar cuenta de una experiencia, alzándose como un "intento por comunicar lo imposible". Por esta insuficiencia paradójica del lenguaje, Beckett recurriría al uso del escenario como una suerte de 'suplemento' que permite "añadir nuevas posibilidades al lenguaje como instrumento del pensamiento y la exploración del ser" (cfr. 64- 65). Con ello, la relación entre lenguaje y acción -entendida por Esslin como la materialización efectiva de la proposición verbal-se convierte en un contrapunto dramático que permite mostrar la dificultad de la comunicación entre los seres humanos y de lograr un conocimiento del yo marcado por la vivencia del transcurrir temporal. A partir de estas consideraciones, propone la interpretación de Fin de partida como una moralidad sobre la muerte que exhibe el agotamiento de un mecanismo en el juego repetitivo de diálogos y situaciones que funcionan como 'patrones', comprendiendo a los personajes como personificaciones de actitudes humanas fundamentales al modo de las piezas medievales. A su vez, la estructura en un solo acto y la ausencia de una acción dramática convertirían a la obra en un monodrama cuya única fuente de tensión radica en saber si Clov tendrá la fuerza para abandonar a Hamm.

La devaluación del lenguaje en tanto condición dramática - examinada por Esslin mucho más exhaustivamente en Esperando a Godot-se muestra para el crítico como síntoma y consecuencia de una época convulsa, que se alza como medio expresivo y que, en su conjunción con el contrapunto escénico, "busca una poesía que ha de surgir de las imágenes concretas y objetivas del escenario" (17). Con ello, la exigencia de la escena se hace primordial para que el lenguaje y su sentido 'aparezcan' tras lo irracional. Precisamente la supuesta mendicidad del lenguaje y su dificultad de significar se ha convertido en el foco de atención de la crítica especializada y en el que nos concentraremos a continuación, para destacar la preeminencia de la dimensión textual que permite proponer a Fin de partida como una obra metateatral.

pieza como ilusión dramática cerrada. La prescindencia de una cuarta pared invisible que separa la ficción de la realidad de los espectadores explicita la dimensión metateatral de la obra, como se precisará en detalle más adelante. 


\section{INDIGENCIA Y PLENITUD DEL LENGUAJE: EL PROBLEMA DEL GÉNERO}

Ya en 1958, un año después del estreno de la pieza de Beckett y tres antes de la célebre publicación de Esslin, Theodor Adorno en su "Intento de entender Fin de partida" abordaba la obra como un drama de la descomposición que se despliega como momento histórico - el posterior a la Segunda Guerra Mundial- mostrándose a sí mismo como el tiempo de la catástrofe, del sinsentido, de la ruina y la supervivencia, y como parodia, entendida ésta como "la utilización de las formas en la época de su imposibilidad" (292). Como descomposición y parodia, Fin de partida disecciona y mutila todos los recursos y componentes dramáticos: el humor, los principios estructurales -exposición, nudo, acción, peripecia, catástrofe-, y particularmente el soporte dramático, el diálogo. En la desaparición del significado del lenguaje ("HAMM: ¿De qué se puede hablar todavía?” (Beckett 233)), más aún, en el temor de llegar a significar algo por medio del lenguaje, y en el juego intermitente de pregunta y respuesta monosilábica que lejos de tensar la curva dramática al modo de la tragedia antigua, distiende y relaja a los interlocutores en disputa, "las palabras suenan como recursos de urgencia porque el enmudecimiento aún no se ha conseguido del todo, como voces acompañantes de un silencio que perturba" (Adorno 293). Si para Esslin el doble sentido y los juegos de lenguaje se perciben como el correlato de un mundo que ha perdido su significado ${ }^{2}$, para Adorno la palabrería que preludia la mudez no es un reflejo mimético de la realidad, sino por el contrario, la verdadera expresión de la catástrofe, en tanto el drama impugna su a priori dramático hasta convertirse en su contrario: "Sólo callando puede pronunciarse el nombre del desastre" (279).

La interpretación iniciada por Adorno tiene proyección en las lecturas críticas de Jean Marie Domenach y Christoph Menke que analizan Fin de partida como una reactualización del género trágico a partir de dos variables ya señaladas por el filósofo de Frankfurt: la época de catástrofe y el lenguaje.

2 La acepción de absurdo con que Esslin aborda el análisis de autores y obras paradigmáticas encuentra sustento en buena medida en la comprensión que formuló el propio Ionesco para caracterizar la obra de Kafka: "Absurdo es lo desprovisto de propósito... Separado de sus raíces religiosas, metafísicas y trascendentales, el hombre está perdido, todas sus acciones se transforman en algo falto de sentido, absurdo e inútil”" (cit. en Esslin 15). 
En El retorno de lo trágico (1969), Domenach plantea que la reemergencia de la tragedia se origina en la época contemporánea de la mano de la parodia y el absurdo, anulando lo que para la forma antigua constituía su singularidad: acción, personaje y lenguaje, por lo que esta nueva tragedia solo puede ser una anti-tragedia o una ante-tragedia. La primera acepción grafica lo que ya Adorno llamó la impugnación del a priori dramático y es para Domenach la forma que adopta un género en un tiempo abortado y muerto, el mismo que se absolutiza en la imposibilidad de conquistar el carácter, la afirmación y la trascendencia por medio del drama. Si la tragedia se afirma en la acción, la ante-tragedia -y Fin de partida en particular- es la tragedia de la misma acción, donde se pone en cuestión el poder de actuar, porque la catástrofe es anterior: "La interrogación que sugiere no es qué sentido, qué falta, qué acción, sino cómo puede haber sentido, falta, acción" (219). Si se impugna no solo el sentido sino también la posibilidad de darlo, si el lenguaje no alcanza a significar, Fin de partida es la expresión soberana de la lucha agónica que emprende la palabra por alcanzar todavía 'una parcela del verdadero yo', vaciando al ser de todo lo que no es lenguaje, multiplicándose en el juego, en el flujo verbal de asociaciones delirantes y en la creación de nuevas combinaciones lingüísticas. Si la indigencia del lenguaje se grafica en su desintegración y multiplicación, su plenitud se restituye allí donde precisamente se vuelve el lazo de lo trágico.

Puesto que este teatro ha reanudado la confrontación del poder del hombre con su destino al único nivel en que aún le era posible: el de la farsa trágica; puesto que enseña a la desesperación a superar sus sobresaltos adolescentes, puesto que lleva hasta el final el infortunio de vivir y la dificultad de hablar, y puesto que habla, devolviendo al lenguaje su soberanía sobre nuestro miserable reino, no le negaremos el nombre de tragedia (232).

Para Christoph Menke, la obra de Beckett se alza como paradigma de la 'forma' en que la tragedia se nos hace contemporánea en nuestro presente, esto es, después de la tragedia, revelando la intrínseca relación que se establece entre el actuar dramático y nuestro actuar, interrogando al teatro como forma de determinación de la realidad. A esta forma la denomina 'tragedia de la representación' o metatragedia, porque al representar la imposibilidad de actuar, la obra se cierra sobre sí misma, levantando la 'cuarta pared' y mostrando el devenir dramático -la acción- como objeto estético distanciado: 
Una tragedia de la representación es una obra teatral que muestra qué puede suceder si el representar se convierte en determinación de la praxis, en una forma de actuar. Las tragedias de la representación muestran que también este actuar puede sucumbir a la ironía trágica del vuelco hacia la desgracia: muestran el destino de la representación. Una tragedia de la representación es una metatragedia porque es una "forma", un género del metateatro: una forma de un teatro, que no solamente es representación sino que trata de la representación que él mismo es. Recoge las condiciones teatrales previas a cualquier tragedia dentro de la tragedia, es más, fundamenta la tragedia a partir de y en sus condiciones teatrales previas: una tragedia de la teatralidad (Menke 189).

Para el autor, Fin de partida se estructura en torno al juego que se despliega entre dos posiciones contrarias, jerárquicas y dependientes, encarnadas por Hamm y Clov y que responde a una doble lógica: la de no-poder-ganar y la de no-poder-acabar. La dependencia mutua y por tanto la insolubilidad del conflicto queda zanjada no por lo que ambos representan, las figuras de amo y esclavo, sino por la utilización que hacen ellos del discurso, elaborando estrategias demoledoras de sentido que mantienen la tensión sin resolverla: "Los intercambios de palabras en Fin de partida no se desarrollan según la determinación clásica del diálogo dramático, esto es, un conflicto entre diferentes posturas, sino que presentan una lucha de prácticas lingüísticas" (229). Así, a la prosa generadora de sentido, al bello hablar de Hamm, se opone el sabotaje lingüístico de Clov, que escarcea e impugna todo sentido posible. La sujeción mutua se fija ya en las estructuras discursivas de poder y contrapoder que ambos ejercen, necesitándose para subsistir, tornando imposible la liberación de Clov. La paralización de la acción, impugnada por ambos personajes a través de las estrategias discursivas, evidencia tanto el fracaso del actuar como el de cualquier intento transformador para la praxis.

La característica autorreflexiva del lenguaje que Menke identifica en Fin de partida y que hace de ella una 'tragedia de la representación' como forma del metateatro, nos parece central en relación con el destino de la representación y el sentido que ella propone como pieza de teatro, en el marco del desarrollo dramático-teatral de las décadas del 40 y 50, cuyas obras, mayoritariamente, se imponen un pronunciamiento sobre la realidad. En este marco, la tesis de Esslin que ve en esta pieza una exposición de la situación humana que pese a su carencia de trama y personajes convencionales logra exhibir un conflicto de naturaleza universal ( cfr. 53 y 58), nos parece 
discutible a la luz de la autoconciencia que explicita la obra, ya que por medio de la autorreflexividad del lenguaje dramático despliega una concepción del drama como metateatro que no recurre a la mimesis tradicional, entendida como recreación de la realidad.

Adoptamos la definición de Abel de metateatro, ya que entiende esta forma como un género específico y no como recurso o estrategia del drama, como sería el "teatro dentro del teatro". En tanto género, tiene su origen en el teatro renacentista y barroco -Shakespeare y Calderón- y se caracteriza por mostrar la realidad de la imaginación dramática, en piezas en que la vida aparece teatralizada. Las obras metateatrales fundamentan su confianza en el poder de la imaginación que pone al mundo entero como un gran escenario, por lo que la conciencia artística se exhibe ex profeso, y el dramaturgo tiene la obligación de reconocer y evidenciar en toda la estructura de la pieza, que es su imaginación la que controla los acontecimientos hasta el final. Al mostrarse la obra como creación, los personajes poseen siempre la conciencia de ser figuras teatrales, inclusive antes que la acción dramática se desarrolle propiamente tal, por lo que se impone la exigencia al destinatario de saberse espectador de la ilusión dramática. Por ende, al insistir en la ilusión creada, el metateatro enfatiza la noción del "mundo" como una proyección de la conciencia humana que, como imagen, no es la última ni definitiva. Esta imagen del mundo opera por ende con una lógica no causal, en que su ordenamiento puede ser improvisado (cfr. Abel 59-61, 113).

En un breve apartado sobre Beckett, Abel considera Fin de partida, Los días felices y La última cinta como piezas metateatrales, sosteniendo:

They conform to the kind of dramatic work I have designated as metatheatre: what makes them so special is that life in these plays has been theatricalized, not by any attitudes taken by the characters, not by any tricks of dramaturgy, and not by the author's intent to demonstrate any propositions about the world, but by the mere passage of time, that drastic fact of ordinary life (85).

La representación del transcurrir como teatralización de la vida constituye para Abel el rasgo que determina a Fin de partida como obra metateatral. Sin embargo, pese a esta afirmación, el crítico no examina la obra para ver en qué medida esto se cumple. A continuación analizaremos la pieza atendiendo a las nociones de juego y reflexividad para ver cómo estas dos determinaciones condicionan el carácter metateatral de la obra, enfatizando la teatralización como artificio ad nauseam. 


\section{JUEGO, AUTORREFLEXIVIDAD Y ARTIFICIOSIDAD: LA DETERMINACIÓN DE LA COMEDIA}

El título del original en francés Fin de partie remite, como lo ha consignado la crítica y el propio autor, al empate técnico 'a tablas' en el juego de ajedrez; en cambio, el título elegido por el autor para su segunda versión en inglés, Endgame, amplía su significación y se vincula directa y estrechamente con la idea de la representación como juego ${ }^{3}$.

En términos culturales, el juego se define según Roger Callois (1994) como actividad sustentada sobre cuatro premisas generales independiente de las formas que adopte -agon, alea, mimicry, ilinx - : la libertad en la participación, su delimitación espacio-temporal, la definición de una estructura con reglas asumidas y la ausencia de finalidad pragmática más allá del placer de la realización misma.

Admitiendo estas condiciones, el juego representacional adquiere su expresión paradigmática bajo la forma de comedia, esto es, un modo de exposición que se caracteriza por su libertad y por su carácter no oposicional ${ }^{4}$.

3 El propio Beckett a propósito de la lectura de Fin de partida como empate del ajedrez señaló: "Hamm is a king in this chess game lost from the start. From the start he knows he is making loud senseless moves. That he will make no progress at all with the gaff. Now at the last he makes a few senseless moves as only a bad player would. A good one would have given up long ago. He is only trying to delay the inevitable end. Each of his gestures is one of the last useless moves which puts off the end. He is a bad player" (cit. en Worton).

La traducción al alemán, Endspiel, refuerza la condición performática: Spiel posee la doble acepción de juego y obra dramática. En español, la obra se ha traducido preservando la denominación del original francés.

Callois agrupa los juegos de representación bajo la categoría de mimicry, que se caracteriza por hacer visible el engaño, donde el sujeto "juega a creer, a hacerse creer o a hacer creer a los demás que es distinto de sí mismo" (52). Para nosotros, la diferencia central entre el juego representacional -drama-y los juegos de representación, radica en que los segundos si bien entran en el juego de la ilusión, permanecen en el plano de la realidad, mientras que el primero se construye y mantiene en el orden de la ficción.

De este modo, a partir de los dos rasgos señalados -libertad y no oposición-establecemos la comedia como forma paradigmática de la representación lúdica. No obstante, recuérdese que los ‘juegos' fueron una forma dramática establecida durante la Edad Media que se caracterizaba por reducir la anécdota dramática al mínimo con la finalidad de proporcionar un pretexto para las canciones, danzas y juegos de destreza, así como contar con personajes que responden a los arquetipos y tipos dramáticos. Como se verá, claramente Fin de partida mantiene la economía de intriga y caracterización en sus personajes propios del juego medieval. 
A diferencia de la tragedia que se estructura bajo la lógica agonal y oposicional que determina el conflicto exhibiendo una forma cerrada - esto es, un desenlace inequívoco producto de su estructura causal y desencadenante-, la comedia presenta una forma abierta que se organiza sobre dobles premisas y dobles resoluciones, por lo que se articula como juego libre sin oposición entre las partes. Su libertad se expresa por una parte, en la independencia de las fábulas de la tradición, lo que facilita la espontaneidad e invectiva, y por otra, en la ausencia de obligatoriedad respecto a la finalidad que impone la acción ${ }^{5}$. La apertura y libertad de la acción cómica permite que ésta se muestre como acción representada, es decir, como juego mimético que hace explícita su condición de artificio, evidenciando su autoconciencia dramática. En el caso de la Comedia Antigua, esta exhibición de la obra como artificio se realiza exclusivamente en la parábasis, momento de suspensión de la ilusión dramática en que ocurre el desplazamiento de un nivel retórico a otro -de la ficción a la realidad, cuando el corifeo se quita la máscara y adelantándose hacia el público dirige sus críticas al ordenamiento político y social-. En el caso de la comedia romántica (véase Der gestiefelte Kater y Die verkehrte Welt, ambas de L. Tieck), las obras se muestran ininterrumpidamente como artificio a través de la ironía y la parodia, presentándose lúdicamente como piezas metateatrales.

Esta dimensión autorreflexiva que hace de Fin de partida una obra metateatral, adopta la lógica y apariencia del juego cómico, pero al mismo tiempo lo impugna y vuelve trágico, al exhibir su artificiosidad ad nauseam, sustentándose en principios estructurales contrarios: la determinación y el pliegue sobre sí misma en oposición a la libertad y apertura.

El conflicto de Fin de partida se establece sucintamente ya en los dos primeros parlamentos que dan inicio al diálogo entre Hamm y Clov: no poder acabar el juego.

Clov: (mirada fija, voz monótona). Acabó, se acabó, acabará, quizás acabe. (Pausa). Los granos se añaden a los granos, uno a uno, y un día,

\footnotetext{
Esta tesis sobre la comedia es desarrollada por August Wilhelm Schlegel, quien además agrega: "Así como lo serio elevado al más alto grado es la esencia de la representación trágica, la broma lo es de la representación cómica. La disposición a la broma es un olvido de todas las oscuras meditaciones en el placentero sentimiento del bienestar presente. Uno debe entonces inclinarse a tomar todo como juego y dejar al alma llevarse livianamente" (cfr. Vorlesungen 42).
} 
de repente, forman un montón, un montoncito, el imposible montón. (Pausa). Ya no me puede castigar. (Pausa). Me voy a mi cocina, tres metros, por tres metros, por tres metros, en espera de que me silbe. (Pausa). Hermosas dimensiones, me apoyaré en la mesa, miraré la pared, en espera de que me silbe.

Hamm: (bostezos). Me... (bostezos) me toca. (Pausa). Jugar (...) (212).

Desde el parlamento inicial de Clov que va dirigido al público, se establece la afirmación sobre "algo" acabado que se relativiza inmediatamente en la inclusión del adverbio. Con el pronunciamiento de Hamm advertimos que ese 'algo' es un juego de carácter imperativo, al estar determinado por un modelo o pauta preestablecida que los participantes deben respetar: el más evidente, los turnos. La alusión de Clov de esperar a que Hamm le silbe, anuncia la relación de dependencia y sometimiento en la que se encuentra y que a poco andar, advertimos es mutua. Con ello, se refuta la libertad como el principio rector del juego, ya que éste aparece como exigencia y necesidad que muestra la interdependencia entre las figuras dramáticas ${ }^{6}$. El asunto se presenta así como un juego entre las partes o un juego entre los roles, que revela la primera característica de esta obra metateatral: la autoconciencia de los personajes como figuras dramáticas. Este grado de autoconocimiento confiere al personaje la percepción de sí mismo como figura, rol y función dentro del asunto o juego del que toma parte.

La caracterización onomástica contribuye a esta conciencia de rol. Los nombres de Clov y Hamm corresponden a dos derivaciones de dos roles

6 Adoptamos la denominación de figura descrita por Manfred Pfister, ya que permite hacer evidente la noción del personaje como constructo que se define por las relaciones que se establecen exclusivamente al interior del texto (con ello, Pfister opone figura a carácter o persona) (cfr. Pfister 220-222). Si bien en ocasiones mantendremos la denominación de personaje por ser una convención dramática, hacemos presente que las figuras dramáticas de esta pieza no responden a la noción del constructo psicológico moderno entendido como personaje. Como señala R. Abirached en relación con los personajes de Beckett, Ionesco, Adamov y Tardieu "el personaje ha sido llevado al grado cero de la personalidad (...) [estos autores] reducen al personaje a su esqueleto social, moral y psicológico de manera tanto más firme cuanto que le privan de todo pasado y de todo porvenir, lo arrancan de la historia de la colectividad a la que pertenece, le suprimen toda posibilidad de trato con el prójimo que no sean desatinos, intercambio de clichés o interrogación impotente. (...) Resulta poco decir que el personaje así trazado rompe con la tradición del teatro burgués. Conserva de la mímesis clásica el procedimiento que suministra los arquetipos y preserva al personaje de degradarse en reflejo del mundo cotidiano" (381-382). 
teatrales. La analogía de 'Clown' con Clov se hace evidente en la actitud farsesca y graciosa propia del payaso que utiliza su corporalidad para generar la risa. La cómica y grotesca condición que le impide sentarse -en oposición a la gravedad y tragicidad de la ceguera y parálisis de Hamm- lo mantienen en escena en un permanente gerundio, en un incesante movimiento que lo lleva a subir y bajar las escaleras, a ir y volver desde la cocina, a tapar y destapar los tarros de basura, a mover de un lado hacia otro la silla del amo ${ }^{7}$. Pero más que a la comicidad gestual del clown, el parásito de Final de partida debe su constitución de figura dramática al rol del bufón, emparentado con el payaso, pero al mismo tiempo muy distante. Mientras el clown no es consciente de su desgracia o simpleza, el bufón -de clara impronta shakespeareana- sí lo es, y en la libertad que le ofrece su condición de 'necio' se apropia de la palabra para distender la acción dramática, y al mismo tiempo replicar. Así, la función servil hacia el señor se matiza en la réplica, crítica y cuestionamiento que realiza, revelando siempre un tipo de conocimiento distinto.

Por otra parte, la figura de Hamm remite a una tipología de actor extravagante y pretencioso - ham actor- que busca exhibir su grandilocuencia en sus 'partes'. Como señala R. McDonald "Hamm is here the 'ham' actor, over-stretching his part, and imbuing his tired lines with a ponderous significance they do not merit" (48). En su parodiada autoconciencia como gran actor, Hamm se hace dueño de la palabra a través de sus monólogos y en la narración de su novela que intenta llevar a cabo. No solo se apropia de ella sino que intenta exhibirse como primera figura en el requerimiento de su aparte y soliloquio, como muestra de mayor profundidad y densidad como personaje ${ }^{8:}$ "HAMM: (colérico) ¡Un aparte! ¡Imbécil! ¿Es la primera vez que oyes un aparte? (Pausa). Inicio mi último soliloquio"(252).

7 El incesante movimiento escénico es propio de las técnicas farsescas, circenses y del music-hall y se desarrolla de forma más aguda en Esperando a Godot.

Tradicionalmente en el drama, por ser el soliloquio un discurso monológico y expresión de una conciencia lúcida, se reserva al protagonista o bien al antagonista, en tanto personajes con un mayor grado de profundidad psicológica y por lo general dinámicos. Ninguna de estas características aplica a Hamm, pero además del carácter metateatral que estas observaciones tienen, adquieren un sentido mayor al ver a Hamm como derivación (o parodia) de Hamlet. Sobre esto volveremos más adelante. 
Esta condición de superioridad que muestra su discurso por sobre el de Clov se ve reforzada en su condición de señor, a la manera de un rey demandante y egocéntrico que tiraniza al extremo a sus súbditos ${ }^{9}$.

Así, el gran actor y el bufón se perfilan, asumen y entran en acción desde la especificidad que encarna su rol. Como señala Clov "Cada uno con lo suyo" (Chacun sa spécialité; everyman his specialty), haciendo alusión a la función que cumple cada rol en el acontecer, tal como en la Comedia del Arte lo hacían las figuras-máscaras individualizadas por su costume y por su función en la generación de la intriga. En Fin de partida las figuras no aparecen individualizadas en su rol por su vestimenta -aun cuando el solideo le da cierto aire ceremonial y grave a Hamm, su bata trasunta cotidianeidad-, pero hay un elemento que fija a Clov como figura teatral. Cuando perturbado por el ruido Hamm pregunta a Clov qué trae en los pies, éste responde 'botines'. La versión original señala brodequins incentivando el guiño metateatral, ya que el brodequin es un tipo de calzado alto usado en la antigüedad por los actores, cuyo sinónimo es precisamente el coturno. Al calzarlos, Clov refuerza su condición de actor en el juego y se fija como figura de la tradición teatral.

Hamm y Clov son un par antitético, concebidos desde sus discapacidades -parálisis, ceguera e imposibilidad de sentarse-, las mismas que demandan la existencia del otro para poder sobrevivir. Si Clov es la realidad sensorial-vista y piernas- de Hamm, éste también se torna indispensable para el siervo, no solo porque fuera del refugio no existe vida ni posibles empleadores, sino porque solo en la interacción -el diálogo en un obra dramática- pueden existir. El bufón 'existe' en la medida en que hay un señor que posibilita su condición como existencia, de allí que solo puede tener realidad como figura dramática, esto es, como personaje que interactúa a través del diálogo en la medida en que el gran actor le da el 'pie' para su intervención. Por ello, el parlamento de Clov dirigido al público que da inicio a la obra, es solo la toma de posición del actor pronto a encarnar su 'papel' en cuanto tenga la indicación escénica y dramática -el silbido- del regisseur que en este caso encarna Hamm en tanto orquestador de la historia o el asunto. Cuando Hamm indica "me toca jugar" da inicio a la acción dramática propiamente,

9 La relación de solidaridad entre el rey y el bufón admite claramente una lectura como reinterpretación de El rey Lear de Shakespeare, interpretación que no es antojadiza dada la red de relaciones intertextuales que establece la pieza con otras obras del dramaturgo inglés, como veremos al final. 
entendida como el curso de acontecimientos que se despliega solo a través de su soporte verbal.

El incesante diálogo que se establece entre ambas figuras, que para Esslin constituye un "zumbido sin sentido", se despoja del carácter de entre-tensión que tiene en Esperando a Godot ${ }^{10}$. Si en ella hablar es un pasatiempo, una forma de hacer sensible el paso del tiempo, en Fin de partida, el diálogo es una vivencia del tiempo dramático, de ese presente que es la evidencia palmaria de su realización como figuras ${ }^{11}$. De allí, que su realización como figuras solo se justifique en el acto dialógico:

CLOV: Te dejo.

HAMM: No.

CLOV: ¿Para qué sirvo?

HAMM: Para replicarme (242).

Si bien la dependencia es mutua y ambos ejercen un poder sobre el otro -Clov posee la capacidad visual y el dominio del tiempo cronológico que le permite manipular a Hamm en sus reportes espaciales y torturarlo con el suministro de sus calmantes determinados por las horas-, quien posee el control es Hamm en tanto actor principal que determina el curso de la acción a través del diálogo y como dramaturgo y regisseur del 'asunto'. Es el amo quien dirige el destino de la acción, movilizando, retomando y forzando el diálogo. A cada amenaza de Clov de partir que implicaría la suspensión del juego, Hamm introduce una pregunta o afirmación que obliga al esclavo a tomar parte del diálogo, sometiéndolo una y otra vez al juego:

10 "VLADIMIR: Ah, sí, ya sé, la historia de los ladrones. ¿La recuerdas?

ESTRAGON: No

VL: ¿Quieres que te la cuente otra vez?

ES: No.

VL: Así matamos el tiempo" (Beckett Esperando a Godot 128).

"ESTRAGON: Entretanto, intentemos hablar sin exaltarnos, ya que somos incapaces de callarnos.

VLADIMIR: Es cierto, somos incansables.

ES: Es para no pensar.

VL: Tenemos justificación.

ES: Es para no escuchar" (175).

11 Siguiendo a Pfister, la acción dramática se realiza siempre en un tiempo presente, por ende el personaje se define como construcción de ese presente de la acción que permanece invariable. 
CLOV: No puedo ir lejos. (Pausa). Te dejo.

HAMM: ¿Está listo mi perro?

CLOV: Le falta una pata.

HAMM ¿Es suave?

CLOV: Es un perro faldero

HAMM: Ve a por él.

CLOV: Le falta una pata.

HAMM: ¡Ve a por él! (Clov sale). Esto mejora (232).

Y en el último diálogo entre ambos:

CLOV: A esto le llamamos encontrar la salida.

HAMM: Te doy las gracias, Clov.

CLOV: (se vuelve, con vivacidad) ¡Ah, perdón, soy yo el que te da las gracias! (256).

Por otra parte, Hamm se muestra como el detentor de la memoria y tiene la percepción más aguda de los cuatro personajes para discernir el tiempo como desgaste y atrofia. Si bien todos se pronuncian sobre el pasado (Nagg y Nell sobre la época en que aún tenían piernas -Nell teatralmente nostálgica y plañidera-, Clov sobre la muerte de la tía Pegg), Hamm es el único que intenta establecer una relación entre el pasado, el presente y el mañana, previendo todavía un futuro, posibilidad que Clov siempre impugna (HAMM: Debería llover./ CLOV: No lloverá; HAMM: Quizá todavía sea demasiado pronto./ CLOV: Si hubieran tenido que germinar, ya lo hubieran hecho. No germinarán. HAMM: La marea subiría./ CLOV: Ya no hay mareas.). Esta percepción diacrónica del flujo temporal es la que determina la actitud de Hamm como narrador de su novela que, en una suerte de 'relación histórica' sería la transposición de la historia de ambos, a través de un lenguaje poético y afectado. La 'memoria' se repite, rectifica y amplifica cada día, no llegando nunca a concluirse. La repetición permanente del mismo argumento novelesco que no admite otros personajes, porque como se pregunta Hamm "dónde encontrarlos" es, en un nivel retórico diferente, el argumento dramático del que ambos forman parte, que también se construye como juego:

HAMM: Adelanté mi historia. (Pausa). La adelanté bastante. (Pausa) Pregúntame dónde voy.

CLOV: Oh. ¿Se trata de tu historia?

HAMM: (muy sorprendido). ¿Qué historia?

CLOV: La que te cuentas desde siempre.

HAMM: Ah, ¿quieres decir mi novela? 


\section{CLOV: ¡Exacto!}

(Pausa).

HAMM: (colérico). ¡Continúa un poco más por favor, continúa un poco más!

CLOV: Supongo que habrás adelantado mucho.

HAMM: (modesto). Oh, no mucho, no mucho. (Suspira). Hay días como éste en los que uno está inspirado. (Pausa). Hay que esperar. (Pausa). Nunca hay que forzarse, nunca hay que forzarse, el resultado es nefasto. (Pausa). Sin embargo, he adelantado un poco. (Pausa). Cuando uno conoce el oficio, ya se sabe. (Pausa. Con énfasis). Sin embargo, repito que he adelantado un poco.

CLOV: (admirado). ¡Muy bien! ¡A pesar de todo, pudiste adelantar un poco!

HAMM: (modesto). Ya sabes, no mucho, no mucho, pero de todos modos, algo es algo (242).

Si bien Clov participa de la narración en tanto destinatario que cada día se dispone a escuchar, intervenir y cooperar en la construcción de esta memoria, se declara cansado de ella, de la misma manera en que lo está de la rutina, de 'sus' historias y de las mismas preguntas y respuestas ("Toda la vida las mismas preguntas, las mismas respuestas" (214), "Estoy harto de nuestras historias, muy harto" (251)). La rutina cotidiana, la vida e historias a las que alude Clov, no son otra cosa que el presente dramático, única realidad posible para un personaje. De allí que el verdadero encadenamiento de Clov sea "la comedia de todos los días", la misma situación dramática que se itera incansablemente y la única por tanto de la que Clov puede tener memoria. Al ser el juego la única realidad factible para ambos, están encadenados al diálogo permanente y repetitivo que se estructura en torno a las mismas preguntas y respuestas y a la conciencia de progresión que tienen del 'asunto'. Por ello, a las preguntas sobre el clima, la hora, la rutina, la comedia y el asunto por parte de Hamm, Clov siempre responderá: la de siempre, la de costumbre.

Frente a la opinión de Michael Worton (1994) quien señala que producto de la reiteración diaria estos personajes no tienen sentido de continuidad, sostenemos que esa conciencia sí existe y es más, se desarrolla en una metarreflexión sobre el tiempo dramático que se elabora y se expone a través de la estructura cíclica que posee la pieza.

El refugio que constituye el espacio dramático del juego aparece como el único enclave donde el tiempo se puede percibir-insistimos, porque es además la única realidad espacial posible para un personaje-. $\mathrm{Si}$, como señala 
Clov, la naturaleza exterior no existe, no hay mareas ni sol, el tiempo vital del ciclo natural de la vida se ha agotado, lo que queda afuera es la muerte, mientras que el refugio se confirma como el único espacio de existencia. Por lo mismo, se vuelve imperiosa la necesidad de constatar y medir cuantitativa y cualitativamente el paso del tiempo. En la narración de su novela-historia, Hamm insiste en los instrumentos de medición -el termómetro, el heliómetro, el anemómetro, el hidrómetro-. Cada vez que los menciona, se busca enfatizar el valor de comprobación que éstos tienen, es decir, el carácter de datos probatorios que confieren una validez a la intriga narrada que supone además, el dominio y el control del narrador sobre ésta y por extensión de la historia o asunto de ambos.

Por otra parte, hay una necesidad de parte de ambos de constatar que la acción dramática transcurre, haciendo explícito que hay una progresión o bien que ésta se detiene:

HAMM: Esto mejora (215).

HAMM: Esto va despacio (217).

CLOV: Algo sigue su curso (218).

HAMM: Esto mejora (218).

CLOV: Esto se anima de nuevo (226).

CLOV: Algo sigue su curso (228).

HAMM: Esto mejora (232).

La permanente referencia a 'esto', se vincula directamente con lo que ellos llaman 'el asunto' o 'nuestro asunto' -en el original chose, y en la versión inglesa thing-. La doble acepción del término que ofrece el español como 'materia tratada' y como 'argumento de una obra' refuerza en el segundo significado el carácter metateatral de la obra, ya que los personajes en el curso de la acción, comprueban a través del diálogo la progresión o detención del movimiento y ritmo dramáticos. De allí que la forma de estructuración y disposición de la textualidad primaria y secundaria sea tan relevante. Salvo los tres monólogos de Hamm y los parlamentos extensos de Nagg cuando cuenta 'historias' - la del sastre y la de Hamm pequeño-, el diálogo se dispone a través de la stycomithia. El intercambio breve, condensado en una línea, que se estructura en torno a la lógica de pregunta y respuesta o de afirmación e impugnación, agiliza el movimiento dramático y retrata a las dos figuras como antagonistas que entran en disputa por la supremacía de $s u$ palabra. Con esto, el carácter lúdico del intercambio verbal que opera en un nivel 
de superficie se anula en la oposición subyacente por el intento de Clov de acabar y de Hamm de continuar.

Por lo mismo, la recurrencia del silencio en las pausas -226 en el textocobra significativa importancia. M. Worton (1994) identifica tres tipos de silencio en la obra: los de represión, cuando el personaje está anonadado por la actitud del interlocutor o por la sensación de estar rompiendo un tabú social; los de inadecuación, cuando los personajes no encuentran qué decir; los de anticipación, cuando esperan la réplica para poder seguir. En los tres casos, no se trata del mensaje que se desea transmitir, sino de la forma y significación que adquiere el lenguaje como forma de dominación y victoria en el juego, así como del carácter autorreflexivo en torno a la obra, el asunto y los personajes como construcciones discursivas, y por tanto metateatrales.

CLOV: (con tristeza). Nunca nadie en el mundo ha pensado de modo tan retorcido como nosotros.

HAMM: Hacemos lo que podemos.

CLOV: Nos equivocamos.

(Pausa).

HAMM: ¿Te crees alguien?

CLOV: Sí, desde luego (217).

HAMM: ¡Clov!

CLOV: (irritado). ¿Qué ocurre?

HAMM: ¿No estamos a punto de... de... significar algo?

CLOV: ¿Significar? ¡Significar, nosotros! (Risa breve). ¡Ésta sí que es buena!

HAMM: Me pregunto. (Pausa). ¿Una inteligencia, que hubiera regresado a la tierra, no se sentiría tentada de formarse ideas a fuerza de observarnos? (Imitando la voz de la inteligencia). ¡Ah, bueno, ya comprendo, sí, veo lo que hacen! (Clov se sobresalta, deja el catalejo y comienza a rascarse el bajo vientre con las manos. Voz normal). E incluso $\sin$ ir tan lejos, nosotros mismos... (emocionado)... nosotros mismos... por momentos... (vehemente)... iY pensar que todo esto quizá habrá servido de algo! (229).

La pregunta de Hamm acerca de la posibilidad de llegar a significar se ha convertido en el argumento central que sostiene la tesis de la desintegración del lenguaje y su vinculación con el absurdo. Esslin, por ejemplo, señala a 
partir de este parlamento que "donde no hay certidumbre no puede haber significados definidos, y la imposibilidad de alcanzar esta certidumbre es uno de los temas principales de sus obras" (64). En una línea similar, Adorno sostiene que "no significar nada se convierte en el único significado. El temor más mortal de los personajes del drama, si no del mismo drama parodiado, es el disimuladamente cómico a que pudieran significar algo" (294).

Los dos pasajes de la obra más arriba citados responden a esta aguda autopercepción de Hamm y Clov como figuras dramáticas, enmarcada en el problema de la trascendencia del personaje dramático. Esta lúcida problemática -desarrollada ya ampliamente en la dramaturgia pirandelliana- pone de relieve el problema de la autonomía y sentido de la ficción dramática en relación directa con su incidencia en la realidad ${ }^{12}$. Este problema se vuelve un aspecto decisivo dentro del metateatro. Ambos pasajes ponen en relación dos dimensiones que aparecen en esta obra como dos planos completamente diferenciados, la ficción y la realidad, materializados en dos espacios: el escenario y la platea. Desde el inicio de la obra, Clov pone en evidencia la conciencia de su rol como personaje en un escenario, cuando dirigiéndose al público señala: "Me voy a mi cocina, tres metros, por tres metros, por tres metros, en espera de que me silbe. (Pausa). Hermosas dimensiones, me apoyaré en la mesa, miraré la pared, en espera de que me silbe". La alusión a las tres paredes que delimitan su espacio, no son otras que las tres paredes de la skené; la cuarta, imaginariamente levantada en el drama realista para sostener la ilusión dramática, es aquí derribada cuando el propio siervo "(desciende de la escalerilla, recoge el catalejo, lo examina, lo apunta hacia el público) y señala: Veo... una multitud delirante". Cuando Clov exclama "nadie en el mundo ha pensado tan retorcido como nosotros" enfatiza esta distancia entre ambas realidades poniendo en evidencia el supuesto carácter ejemplar o modelador del drama. Por ello la pregunta irónica de Hamm ¿te crees alguien? relativiza la condición del personaje y también del drama, no solo como elementos 'significantes', sino también como elementos trascendentes. En la interrogante acerca de la posibilidad de significar algo para alguien se repone claramente la antigua pregunta sobre el teatro como

12 Por esta razón, tanto el drama de Pirandello como Fin de partida pueden ser consideradas piezas de la dramática trascendental, aquella que indaga en el problema del saber y el conocer, a partir de la dificultad de pronunciarse sobre la realidad como una construcción última y definitiva (Sobre la dramática trascendental, véase Menke 75 y ss). 
medio de intervención de la realidad ${ }^{13}$. De allí el juego imaginario sobre una inteligencia que volviera a la tierra y se hiciera la pregunta acerca del sentido de las acciones de estas figuras. Esta hipotética situación imaginaria en la que se alude a un posible espectador, tal como el que está sentado en la platea, hace explícito al destinatario su condición de existencia real frente a estas creaciones imaginarias.

Señalamos al principio que el metateatro, al hacer visible su condición como artificio, enfatiza la noción del 'mundo' como una imagen -creaciónque no es la última ni definitiva, por lo que el drama no necesariamente se plantea como ficción mimética de la realidad. En la observación de Hamm: "E incluso sin ir tan lejos, nosotros mismos... (emocionado)... nosotros mismos... por momentos... (vehemente)... ¡Y pensar que todo esto quizá habrá servido de algo!" se establece la autonomía de la ficción, de la misma manera que cuando le pide a Clov que lo "haga dar vueltas al mundo" recorriendo el refugio apegándose a las tres paredes.

Cuando L. Abel considera esta pieza como una obra metateatral, enfatiza que no es porque establezca proposiciones sobre el mundo -función que directa o indirectamente se arroga la ficción mimética-, sino por representar el paso del tiempo, el hecho más tangible de la existencia cotidiana.

Si la existencia se define como ser en el tiempo, la acción que define la naturaleza humana es la de experimentar el transcurrir temporal, dimensión que en Fin de partida queda abolida en tanto el único tiempo posible es el presente que define a las figuras dramáticas; presente que se refuerza en la estructura cíclica de la obra ${ }^{14}$. La pieza se abre y concluye de la misma forma y con los mismos parlamentos: Hamm en el centro del escenario, al principio quitándose el pañuelo que lo cubre y al cierre, desdoblándolo para taparse el rostro, Clov al principio refiriéndose a la acumulación del tiempo y Hamm al final enfatizando la inutilidad de esa suma. En la parodia a la paradoja de Zenón verbalizada por Clov: "Los granos se añaden a los granos, uno a uno, y un día de repente forman un montón, un montoncito, el imposible

13 Función modeladora o reflexiva que se arroga el drama antiguo y moderno, inclusive en obras próximas a Beckett, como las piezas brechtianas o existencialistas.

14 Si bien Esperando a Godot también posee una estructural circular, la disposición en dos actos permite una aprehensión del transcurrir temporal. No solo anochece en cada acto -dimensión que no podemos aquilatar en Final de partida-, sino que entre un acto y otro observamos la huella del tiempo en los personajes -la decrepitud y ceguera de Pozzo y la mudez de Lucky- y en la representación de la naturaleza: la germinación del árbol. 
montón", se expresa la percepción del tiempo como devenir, progresión y acumulación que pierde su condición significativa en tanto se vuelve inútil. La imagen no es otra que la imposibilidad de una experiencia significante dada la acción rutinaria, cíclica e idénticamente repetida. Por otra parte, cuando Hamm advierte en su monólogo "El fin está en el principio y sin embargo uno continúa", establece la sentencia y el destino de ellos como personajes condenados al juego iterativo; y un poco más adelante cuando atrae la referencia a Zenón una vez más y señala "Minuto a minuto, pluf, pluf, como los granos de (piensa)... aquel antiguo griego, y toda la vida uno espera que eso la represente", refuerza el destino trágico de estas figuras teatrales. Si para el drama antiguo, y la tragedia en particular, su función modeladora radicaba en mostrar un proceso en virtud del cual el personaje experimentaba un cambio que servía de ilustración y aprendizaje para el espectador ${ }^{15}$, estas dos figuras dramáticas en tanto roles condenados a un juego solo son espejos para sí mismas en la medida en que asumen la imposibilidad de progresión que implique un cambio en sus relaciones y en las condiciones establecidas de antemano para ellos. La imposibilidad de una experiencia significante (el imposible montón) en tanto exhibición de una cantidad y/o variedad de situaciones vividas por los personajes que trascienda la skené, se hace inviable para dos figuras condenadas a un conflicto trágico ${ }^{16}$ : a los "instantes nulos, siempre nulos, pero que cuentan, pues la cuenta está hecha y la historia terminó" (256). Por ello, cada vez que ambos aluden a la 'jornada' (journée) se refuerza esta noción de un tiempo significativo, entendiendo por jornada no solo la delimitación cronológica de veinticuatro horas, sino la suma de acontecimientos en ella contenidos. Cuando Hamm dice "este fin de jornada es uno de tantos" (218), sugiere la sempiterna y trágica repetición de la misma acción lúdica que, en la traducción al español, se refuerza además por la

15 La acción representada en la tragedia se distingue por presentar siempre un cambio -metábasis- que permite el paso de la dicha al infortunio o viceversa verosímilmente en una duración determinada. Por ello la acción dramática es un proceso que experimenta el personaje y aprehende el espectador que, según Aristóteles, posibilita la adquisición de un aprendizaje.

16 Señalamos como conflicto trágico la permanencia y dependencia mutua. Este conflicto no tiene carácter dramático, ya que para poder definirlo como tal, es necesario que las dos fuerzas colisionen y tras el choque, entren en reposo. Si bien Hamm y Clov se perfilan agonalmente, la oposición es absolutamente complementaria sin llegar nunca a disolverse por el carácter cíclico. Aunque la última imagen de Clov es vestido de chaqueta con impermeable, maleta y paraguas, parado en la puerta, frente al último pie de Hamm, se vuelve vivamente, esto es, se dispone a tomar parte del juego nuevamente. 
connotación teatral que tiene: jornada es también el nombre que reciben los actos en la comedia del siglo de oro español.

\section{LA SOBERANÍA DEL LENGUAJE DRAMÁTICO}

Hasta aquí hemos señalado cómo Final de partida en tanto pieza metateatral se exhibe a sí misma en su representación como obra dramática y no como representación de la vida ${ }^{17}$. Por esta razón, toda posibilidad de 'significar' debe establecerse en relación con los referentes que establece la propia obra que, en este caso, corresponden a una dimensión metaliteraria y metateatral. Como el propio Hamm declara, él nunca ha estado fuera -el espacio que circunda al refugio y que por extensión es el mundo fuera del teatro-, por lo que difícilmente sus palabras pueden tener significado para una inteligencia exterior y sentido fuera de una obra que se muestra como drama.

Fin de partida no es solo una pieza que manifiesta su autoconciencia como obra dramática en la exhibición del juego entre dos roles, sino que reflexiona sobre el drama desde el elemento que lo constituye y conforma una tradición: el lenguaje.

Se ha insistido desde Esslin y Adorno en la ausencia de significado del lenguaje de esta pieza, pero esa supuesta ausencia solo es tal, cuando el parámetro para aquilatar el discurso dramático es su proyección e incidencia en la realidad.

Cuando Hamm interrumpe furioso la 'historia' del sastre contada por Nagg, exclama agotado: “¿No han terminado? ¿No van a terminar nunca? (Súbitamente furioso.) ¡No terminarán nunca! (Nagg se hunde en el cubo de basura y lo tapa. Nell no se mueve.) Pero ¿de qué pueden hablar? ¿De qué pueden hablar todavía? (Frenético.) ¡Mi reino por un basurero!” (223).

La pregunta "de qué pueden hablar todavía" no remitiría a un retoricismo ante la falta de sentido en un mundo en total descomposición, como se desprende de la tesis de Adorno (cfr. 294 y ss.). Por el contrario, la interrogante se carga de un sentido metaliterario por sobre la dimensión metalingüística, al venir inmediatamente secundada por un intertexto claramente advertible

17 Recuérdese que para Aristóteles el drama en tanto imitación de acciones es mimesis de vida, por lo que la fábula representada en la escena tiene una proyección que trasciende los límites de la skené (cfr. el segundo y cuarto capítulo de la Poética). 
para cualquier lector/espectador de drama: el requerimiento de Ricardo III de Shakespeare. No es casual que gran parte de los intertextos en esta pieza provengan de la dramaturgia shakespeareana ${ }^{18}$ : el ya citado, la afirmación de Clov como recepción de La tempestad "Empleo las palabras que me has enseñado. Si ya no significan nada, enséñame otras. O deja que me calle", y la penúltima frase de Hamm "no hablemos más" en un diálogo con la última intervención de Yago en Otelo: "A partir de este momento no pronunciaré ni una palabra" y como reverberación del último parlamento de Hamlet: "el resto es silencio".

Si bien pareciera que el lenguaje no alcanza a significar, la pregunta de Hamm es una indagación que se hace el propio autor sobre la posibilidad de decir algo que en la historia del drama no haya sido dicho ya. En su diálogo con la tradición dramática -encarnada paradigmáticamente en los textos de Shakespeare, otro gran autor de piezas metateatrales- pareciera ser que lo que queda es solo el silencio, como lo corrobora Hamm en su última parte en un eco hamletiano. Mientras para Hamlet solo queda silencio tras la ejecución de una acción largamente dilatada, para su derivación onomástica mutilada, Hamm, el silencio se convierte en la imposibilidad de trascender como personaje dramático en el juego dialógico y para Beckett, en la constatación del lenguaje como realidad única. Si el tiempo y la existencia es lenguaje, nada hay fuera de él, por lo que su fuerza expresiva se patentiza precisamente en el límite que constituye el silencio, mostrándose trágicamente en Final de partida en su absoluta plenitud.

$\mathrm{Si}$, como señala Worton, todo texto de Beckett está construido sobre la premisa que cada vez que hablamos y escribimos estamos usando los pensamientos y lenguajes de otros, por lo que estamos condenados a construirnos a través de los discursos de otros, en Fin de partida esta determinación se agudiza al punto en que como figuras dramáticas conscientes, estos personajes no pueden escapar al sino de sentir que están 'pasando un texto' ${ }^{19}$. Texto que por una parte es el guión que les ha sido asignado, su juego, así como la suma de textos que la tradición dramática les provee.

18 Worton aborda la paradoja de Zenon, el cogito cartesiano, el "Esse est percibi" de Berkeley, la sentencias bíblicas y la doxología cristiana en Esperando a Godot y Final de partida como intertextos parodiados.

19 'Pasar el texto' se reconoce como una estrategia de actuación en que el actor repasa mecánicamente el guión para marcar posiciones, giros, etc. Como técnica de ensayo, comprueba la asimilación y memoria del texto y no su 'actuación'. 
En ese sentido, resulta altamente sugerente la 'vuelta de tuerca' que realiza Beckett en la exploración del lenguaje dramático. Frente a la búsqueda de nuevos lenguajes escénicos del teatro de vanguardia y corrientes contemporáneas al autor, así como frente a la concepción de la palabra como imprecación o compromiso en el teatro de situaciones, el dramaturgo irlandés insiste en auscultar las potencialidades de la acción verbal como sostén dramático. En sus palabras: "The best possible play is one in which there are no actors, only the text. I'm trying to write one".

\section{BIBLIOGRAFÍA}

Abel, Lionel. Metatheatre. A New View of Dramatic Form. New York: Hill and Wang, 1963.

Abirached, Robert. La crisis del personaje en el teatro moderno. Madrid: Publicaciones de la asociación de directores de escena de España. Serie: Teoría y práctica del teatro, 1994. Aristóteles. Poética. Trad. de Valentín García Yebra. Madrid: Gredos, 1974.

Adorno, Theodor. "Intento de entender Final de partida". Notas sobre Literatura II. Madrid: Eds. Akal, 2003.

Beckett, Samuel. Endgame. New York: Grove Press, 1958.

Fin de partie. Paris: Les Éditions de Minuit, 1975.

Teatro reunido. Eleutheria. Esperando a Godot. Fin de partida. Pavesas. Film. Buenos Aires: Tusquets, 2006.

Callois, Roger. Los juegos y los hombres. La máscara y el vértigo. México: F.C.E., 1994.

Domenach, Jean Marie. El retorno de lo trágico. Barcelona: Eds. Península, 1969.

Esslin, Martin. El teatro del absurdo. Barcelona: Seix Barral, 1966.

McDonald, Ronan. The Cambridge Introduction to Samuel Beckett. Cambridge: C.U.P., 2006.

Menke, Cristoph. La actualidad de la tragedia. Ensayo sobre juicio y representación. Madrid: Visor, 2008.

Pfister, Manfred. Das Drama. Theorie und Analyse. Stuttgart: Wilhelm Fink Verlag, 2001.

Schlegel, August Wilhelm. Vorlesungen über Dramatische Kunst und Literatur. Kritische Schriften und Briefe. Stuttgart-Berlin-Mainz-Köln: W. Kohlhammer Verlag, 1966.

Worton, Michael. "Waiting for Godot and Endgame: Theatre as Text". The Cambridge Companion to Beckett. Ed. by John Pilling. Cambridge: C.U.P, 2004 67-87. Disponible en: http://web.archive.org/web/20010128075500/http://www.cyberuni.vu/wormi001.html 